\title{
Preparation of Poly(arylenediamine)s by Palladium-Catalyzed Polycondensation of Aryl Dibromides with Secondary Diamines
}

\author{
Takaki Kanbara, ${ }^{\dagger}$ Kiyoaki Izumi, Tomoko Narise, and Kiyoshi Hasegawa \\ Department of Chemical and Biochemical Engineering, Faculty of Engineering, \\ Toyama University, 3190 Gofuku, Toyama 930, Japan
}

(Received July 24, 1997)

KEY WORDS Polycondensation / Palladium Complex / Polyamine / Aryl Dibromides / Secondary
Diamines /

Numerous reports have been published on palladium (Pd) complex catalyzed polycondensation to give poly(arylene)s, polyesters, polyamides, and related polymers. ${ }^{1}$ However, the preparation of polyamines using Pd-catalyzed processes has been little studied. ${ }^{2}$ We have recently reported that the Pd-catalyzed polycondensation of dibromobenzenes with secondary diamines affords poly(arylenediamine)s. ${ }^{3}$

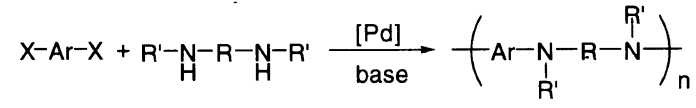

However, the yields and molecular weights of the obtained polymers are not high. A mechanism for the Pd-catalyzed aryl amination has been proposed, ${ }^{4}$ and the catalyst system involves $\beta$-hydrogen elimination reaction of the $\mathrm{Pd}$ intermediate. The undesirable side reaction should be depressed to achieve high molecular weights in the polycondensation.

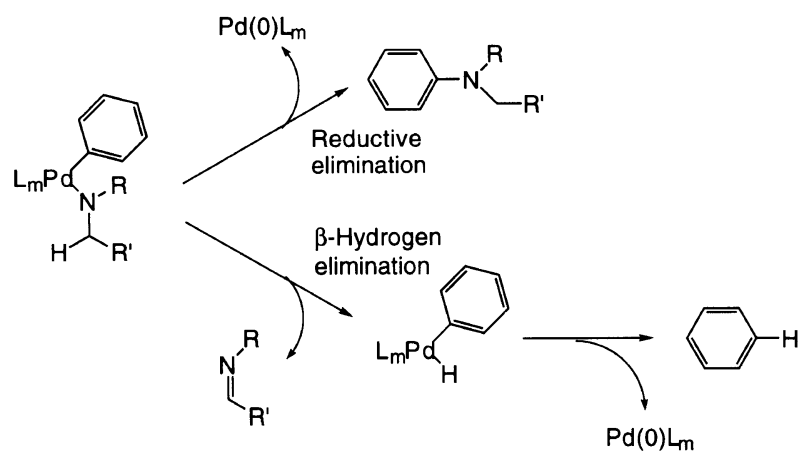

Reports on Pd-catalyzed aryl amination have demonstrated mechanisms of the reaction and improved catalyst systems. $^{4,5}$ In the course of our investigation on the Pd-catalyzed polycondensation, we found that the combination of tris(dibenzylideneacetone)dipalladium(0) $\left(\operatorname{Pd}_{2}(\mathrm{dba})_{3}\right)$ and bulky phosphine ligands such as tri-o-tolylphosphine $\left(\mathrm{P}(o \text {-tolyl })_{3}\right)$, tri-tert-butylphosphine $\left(\mathrm{P}(t \text {-butyl })_{3}\right)$, and $2,2^{\prime}$-bis(diphenylphosphino)-1, $1^{\prime}$ binaphthyl (BINAP) serves as superior catalyst systems for the polycondensation, and affords a variety of poly(arylenediamine)s with higher molecular weights in higher yields than previously reported examples. We report the results of the $\mathrm{Pd}$-catalyzed polycondensation

$\dagger$ To whom all correspondence should be addressed. in the following.

\section{EXPERIMENTAL}

IR and NMR spectra were recorded on a JASCO FT-IR-230 spectrometer, JEOL JNM-A400 NMR spectrometer, respectively. Elemental analyses were carried out with a Yanaco CHN Corder MT-5 and a Mitamura Riken Kogyo Micro Elementary Analyzer. GPC analyses were performed with a JASCO 880 system using a Shodex K-804L column using $\mathrm{CHCl}_{3}$ as an eluent (polystyrene standards). Number-average molecular weights of the samples were measured by a Knauer vapor pressure osmometer Type 11.00 in $\mathrm{CHCl}_{3}$ at $30^{\circ} \mathrm{C}$.

A mixture of 1,3-dibromobenzene (472 mg, $2 \mathrm{mmol})$ and 4,4'-trimethylenedipiperidine (4,4'-TMDP) (421 mg, $2 \mathrm{mmol})$ was dissolved in toluene $(15 \mathrm{ml})$. $\mathrm{NaO} t \mathrm{Bu}$ (577 mg, $6 \mathrm{mmol}), \mathrm{Pd}_{2}(\mathrm{dba})_{3}(45.8 \mathrm{mg}, 0.05 \mathrm{mmol})$, and $\mathrm{P}(o \text {-tolyl })_{3}(91 \mathrm{mg}, 0.3 \mathrm{mmol})$ were added to the solution at room temperature. The reaction mixture was stirred at $100^{\circ} \mathrm{C}$ for $16 \mathrm{~h}$ under nitrogen. After cooling to room temperature, the mixture was quenched by adding aqueous ammonia $(20 \mathrm{ml})$ and the product was extracted with $\mathrm{CHCl}_{3}(30-40 \mathrm{ml})$. The organic fraction was concentrated and reprecipitation from $\mathrm{CHCl}_{3} /$ hexane and $\mathrm{CHCl}_{3}$ /ether gave a yellow powder of poly $\left[1,1^{\prime}-\right.$ (4,4'-trimethylenedipiperidinediyl)-1,3-phenylene $]$ (501 mg, $88 \%$ yield). Anal. Calcd for $\left(\mathrm{C}_{19} \mathrm{H}_{28} \mathrm{~N}_{2}\right)_{n}$ : C, $80.2 \%$; H, 9.9\%; N, 9.8\%. Found: C, 79.1\%; H, 9.8\%; N, 9.1\%; $\mathrm{Br}, 0.8 \% .{ }^{1} \mathrm{H} \mathrm{NMR}\left(\mathrm{CDCl}_{3}, \mathrm{ppm}\right): \delta=1.0-1.5(12 \mathrm{H})$, $1.8(4 \mathrm{H}), 2.7(4 \mathrm{H}), 3.6(4 \mathrm{H}), 6.4(2 \mathrm{H}), 6.5(1 \mathrm{H}), 7.1(1 \mathrm{H})$. ${ }^{13} \mathrm{C} \mathrm{NMR}\left(\mathrm{CDCl}_{3}, \mathrm{ppm}\right): \delta=23.8,32.4,35.7,36.7,50.5$, $105.8,108.4,129.2,153.0$. The preparation of other poly(arylenediamine)s was carried out similarly. The $\mathrm{CHCl}_{3}$ insoluble fraction of the polymers was purified by washing thoroughly with aqueous ammonia, hexane, and ether followed by reprecipitation from formic acid/ aqueous ammonia.

\section{RESULTS AND DISCUSSION}

Table I summarizes the results of the Pd-catalyzed polycondensation of 1,3-dibromobenzene with 4,4'TMDP using various catalyst systems. In the present study, use of catalyst systems generated from $\mathrm{Pd}_{2}(\mathrm{dba})_{3}$ and $\mathrm{P}(o \text {-tolyl })_{3}$ or $\mathrm{P}(t \text {-butyl })_{3}$ was found to give 
Table I. Pd-catalyzed polycondensation of 1,3-dibromobenzene with $4,4^{\prime}$-trimethylenedipiperidine ${ }^{\mathrm{a}}$

\begin{tabular}{|c|c|c|c|c|}
\hline \multirow{2}{*}{ Run } & \multirow{2}{*}{ Ligand } & Yield $^{\mathrm{b}}$ & \multirow{2}{*}{$\begin{array}{c}M_{n}^{\mathrm{c}} \\
\times 10^{-3}\end{array}$} & \multirow{2}{*}{$\begin{array}{l}M_{w}{ }^{\mathrm{c}} \\
\times 10^{-3}\end{array}$} \\
\hline & & $\%$ & & \\
\hline 1 & $\mathrm{P}(o \text {-tolyl })_{3}$ & 88 & 6.9 & 10.5 \\
\hline 2 & $\mathrm{P}(t \text {-butyl })_{3}$ & 76 & 6.7 & 11.4 \\
\hline 3 & $\mathrm{PPh}_{3}$ & 3 & 1.7 & 2.1 \\
\hline 4 & BINAP & 58 & 5.1 & 6.4 \\
\hline 5 & DPPF & 49 & 3.9 & 5.7 \\
\hline 6 & DPPP & 3 & 1.5 & 1.8 \\
\hline 7 & DPPE & 4 & 3.4 & 4.1 \\
\hline $8^{\mathrm{d}}$ & $\mathrm{P}(o \text {-tolyl })_{3}$ & 51 & 4.5 & 5.9 \\
\hline $9^{e}$ & $\mathrm{P}(o \text {-tolyl })_{3}$ & 45 & 3.2 & 4.1 \\
\hline
\end{tabular}

a Polycondensation was carried out in the presence of $\mathrm{NaO} t \mathrm{Bu}$ (3 equiv. for monomer), $\mathrm{Pd}_{2}(\mathrm{dba})_{3}(2.5 \mathrm{~mol} \%$ for monomer $)$, and ligand $(\mathrm{P} / \mathrm{Pd}$ ratio $=3 / 1)$ in toluene at $100^{\circ} \mathrm{C}$ for $16 \mathrm{~h}$. ${ }^{\mathrm{b}}$ Insoluble fraction in ether. ${ }^{\mathrm{c}}$ Determined by GPC with polystyrene standards. ${ }^{\mathrm{d}}$ Reaction was run with $\mathrm{PdCl}_{2}\left[\mathrm{P}(o \text {-tolyl })_{3}\right]_{2}(5 \mathrm{~mol} \%$ for monomer $)$ as the catalyst. $\quad{ }^{\mathrm{e}}$ Reaction was run with $\mathrm{Pd}(\mathrm{OAc})_{2}$ ( $5 \mathrm{~mol} \%$ for monomer $)$ and $\mathrm{P}(o \text {-tolyl })_{3}$ (3 equiv. for $\left.\mathrm{Pd}(\mathrm{OAc})_{2}\right)$ as the catalyst.

significant improvement in the yields and molecular weights of the polymer. When $\mathrm{Pd}(\mathrm{II})$ catalysts such as $\mathrm{PdCl}_{2}\left[\mathrm{P}(o \text {-tolyl })_{3}\right]_{2}$ are used, the formation of arene from aryl bromide during reduction of the $\mathrm{Pd}(\mathrm{II})$ precursor to $\mathrm{Pd}(0)$ occurs. $^{4 a}$ In situ formed zerovalent $\operatorname{Pd}$ complex, $\operatorname{Pd}(0) \mathrm{L}_{\mathrm{m}}$, is considered to suppress the undesirable reactions. Improvement of yield and molecular weight for the polycondensation was also observed in the reaction catalyzed by the combination of $\mathrm{Pd}_{2}(\mathrm{dba})_{3}$ and BINAP, while other monodentate or bidentate phosphine ligands such as triphenylphosphine $\left(\mathrm{PPh}_{3}\right)$, 1,1'-bis(diphenylphosphino)ferrocene (DPPF), 1,3-bis(diphenylphosphino)propane (DPPP), and 1,2bis(diphenylphosphino)ethane (DPPE) were less effective. The efficiency of bulky chelating bis-phosphine ligands is considered due to inhibition of side reactions such as $\beta$-hydrogen elimination from an amidopalladium intermediate. ${ }^{5 a-c}$

Use of $o$-xylene as a solvent also gave the polymer in a good yield, while reactions in dioxane and 1,2-diethoxyethane afforded lower yields of the polymer, and $N, N$-dimethylformamide (DMF) did not give the product. Use of base weaker than $\mathrm{NaO} t \mathrm{Bu}$ such as $\mathrm{K}_{2} \mathrm{CO}_{3}$ gave the product in lower yield, and employing $\mathrm{Et}_{3} \mathrm{~N}$ failed to promote the polycondensation.

The results of the $\mathrm{Pd}$-catalyzed polycondensation of various aryl dibromides with secondary diamines are summarized in Table II. Polycondensation using the present catalyst systems $\left(\mathrm{Pd}_{2}(\mathrm{dba})_{3} / \mathrm{P}(o \text {-tolyl })_{3}, \mathrm{Pd}_{2}-\right.$ $(\mathrm{dba})_{3} / \mathrm{P}(t \text {-butyl })_{3}$, and $\left.\mathrm{Pd}_{2}(\mathrm{dba})_{3} / \mathrm{BINAP}\right)$ resulted in much higher yields than that of the previous report when $\mathrm{PdCl}_{2}\left[\mathrm{P}(o \text {-tolyl })_{3}\right]_{2}$ was used. ${ }^{3}$ The structures of the polymers were confirmed by IR and NMR spectroscopy. Some polymers contain a $\mathrm{CHCl}_{3}$ insoluble fraction with high molecular weight, but it is soluble in acidic solvents such as formic acid. The IR spectrum of the insoluble fraction is identical to that of the $\mathrm{CHCl}_{3}$ soluble fraction.

As shown in Table II, the reactions using cyclic secondary diamines such as 4,4'-TMDP and piperazine gave the products in good yields, while the reactions using less nucleophilic acyclic secondary diamines re-
Table II. Pd-catalyzed polycondensation of aryl dibromides and secondary diamines

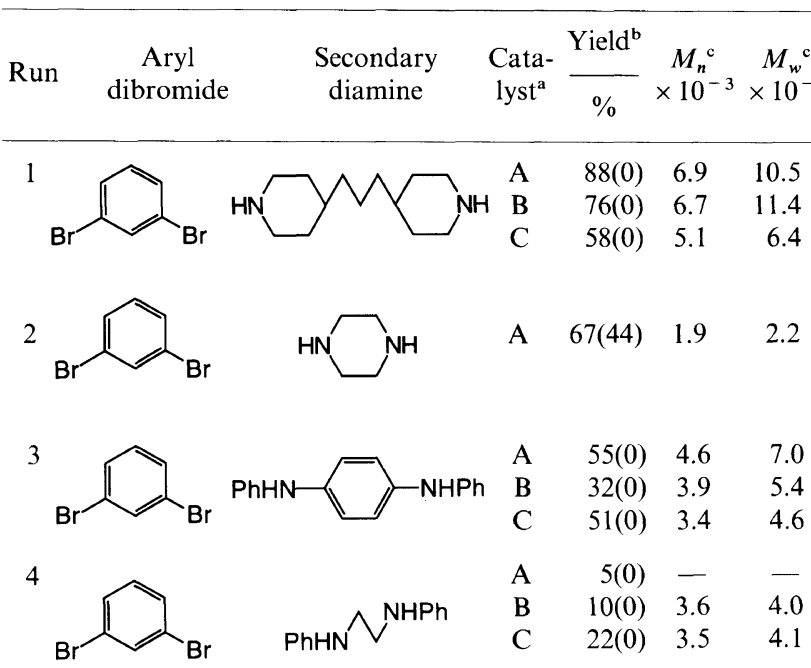

$6 \mathrm{Br} \longrightarrow \mathrm{Br}$<smiles>Cc1cc(Br)c(C)cc1Br</smiles>
等r $\begin{array}{llll}\mathrm{A} & 60(0) & 2.7 & 4.7 \\ \mathrm{BH} & 68(0) & 2.7 & 4.7\end{array}$

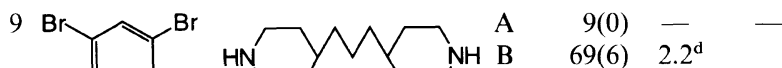
$61(12) \quad 2.9^{\mathrm{d}}$

10

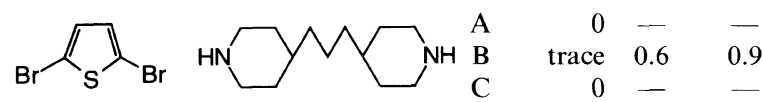

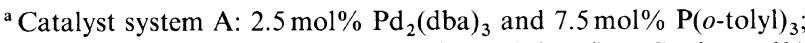
B: $2.5 \mathrm{~mol} \% \quad \mathrm{Pd}_{2}(\mathrm{dba})_{3}$ and $7.5 \mathrm{~mol} \% \mathrm{P}(t \text {-butyl })_{3} ; \quad \mathrm{C}: 2.5 \mathrm{~mol} \%$ $\mathrm{Pd}_{2}(\mathrm{dba})_{3}$ and $3.8 \mathrm{~mol} \%$ BINAP. ${ }^{\mathrm{b}}$ Total yield; the number in the parentheses is the yield of $\mathrm{CHCl}_{3}$ insoluble fraction. ${ }^{\mathrm{c}}$ Soluble fraction in $\mathrm{CHCl}_{3}$; determined by $\mathrm{GPC}$ with polystyrene standards. ${ }^{\mathrm{d}}$ Determined by VPO in $\mathrm{CHCl}_{3}$ at $30^{\circ} \mathrm{C}$.

sulted in little or no product formation (Runs 4, 5). In contrast, use of $N, N^{\prime}$-diphenyl-p-phenylenediamine as monomer afforded the polymer in moderate yield (Run $3)$. Use of the aromatic diamine would depress the $\beta$-hydrogen elimination of the Pd intermediate.

Electronic properties of aryl dibromides may affect the polycondensation. Polycondensation using electron-rich aryl dibromide, 2,5-dibromothiophene, with 4,4'-TMDP gave only a trace of oligomeric product. In contrast, use of 2,6-dibromopyridine and 3,5-dibromopyridine, which have a $\pi$-electron deficient pyridine ring, provided polymers in moderate yields. Electron-poor aryl bromides have been found to give higher yields of arylamines than electron-rich aryl bromides for the Pd-catalyzed aryl amination of aryl bromides. ${ }^{4 a, 5 b}$ Although pyridine inhibits the Pd-catalyzed aryl amination due to dis- 
placement of ligand from the catalytic intermediates, ${ }^{5 c}$ the present catalyst systems may suppress the ligand exchange during the polycondensation.

In summary, we demonstrated that the combination of $\mathrm{Pd}_{2}(\mathrm{dba})_{3}$ and bulky phosphine ligands $\left(\mathrm{P}(o \text {-tolyl })_{3}\right.$, $\mathrm{P}(t \text {-butyl })_{3}$, and BINAP) serves as an efficient catalyst system for the polycondensation of aryl dibromides with secondary diamines. This procedure should broaden the scope of polyarylamine preparation.

Acknowledgment. The authors are grateful for the financial support by a Grant-in-Aid (No. 09750972) from the Ministry of Education, Science, and Culture of Japan.

\section{REFERENCES}

1. A.-D. Schlüter and G. Wegner, Acta Polym., 44, 59 (1993); T. Yamamoto, J. Synth. Org. Chem. Jpn., 53, 999 (1995); Prog.
Polym. Sci., 17, 1153 (1992); M. Yoneyama, M. Kakimoto, and Y. Imai, Macromolecules, 22, 2593(1989); ibid., 21, 1908 (1988).

2. M. Suzuki, J.-C. Lim, M. Oguni, A. Eberhardt, and T. Saegusa, Polym. J., 22, 815 (1990); T. Yamamoto, S.-B. Kim, and T. Maruyama, Chem. Lett., 413, (1996).

3. T. Kanbara, A. Honma, and K. Hasegawa, Chem. Lett., 1135 (1996).

4. (a) J. F. Hartwig, S. Richards, D. Barañano, and F. Paul, J. Am. Chem. Soc., 118, 3626 (1996); (b) J. Louie, F. Paul, and J. F. Hartwig, Organometallics, 15, 2794 (1996); (c) A. S. Guram, R. A. Rennels, and S. L. Buchwald, Angew. Chem. Int. Ed. Engl., 34, 1348 (1995); (d) S.-H. Zhao, A. K. Miller, J. Berger, and L. A. Flippin, Tetrahedron Lett., 37, 4463 (1996).

5. (a) J. P. Wolfe, S. Wagaw, and S. L. Buchwald, J. Am. Chem. Soc., 118, 7215 (1996); (b) M. S. Driver and J. F. Hartwig, ibid. 118, 7217 (1996); (c) S. Wagaw and S. L. Buchwald, J. Org. Chem., 61, 7240 (1996); (d) J.-F. Marcoux, S. Wagaw, and S. L. Buchwald, ibid., 62, 1568 (1997); (e) Y. D. Ward and V. Farina, Tetrahedron Lett., 39, 6993 (1996); (f) C. A. Willoughby and K. T. Chapman, ibid., 39, 7181 (1996); (g) T. Yamamoto, M. Nishiyama, and Y. Koie, Jpn. Patent Appl., 119477, 97450, and 97451 (1997). 